Dinamika Kesehatan Jurnal Kebidanan dan Keperawatan Vol 10 No. 1 Juli 2019 ( ISSN: 2086-3454 EISSN: 2549-4058)

url: http://ojs.dinamikakesehatan.unism.ac.id DOI : https://doi.org/10.33859/dksm.v10i1.390

Perbedaan Intensitas Nyeri Sebelum dan Sesudah Ambulasi Dini pada Ibu Postpartum Post Seksiosesar

\title{
Perbedaan Intensitas Nyeri Sebelum dan Sesudah Ambulasi Dini pada Ibu Postpartum
} Post Seksiosesar

\author{
Regina VT Novita 1, Megawati Saragih 2 \\ 1,2 Sekolah Tinggi Ilmu Kesehatan Sint Carolus \\ *correspondence author: Telepon: 0511-3268105, E-mail: regina_vita@yahoo.com, \\ DOI: https://doi.org/10.33859/dksm.v10i1.390
}

\begin{abstract}
Abstrak
Latar Belakang: Ibu dengan seksio sesar memiliki intensitas nyeri yang tinggi akan menghambat bounding attachment terhadap bayinya dan perawatan terhadap dirinya sendiri. Ambulasi dini yang dimulai 6- 12 jam post seksio sesar akan mempercepat proses penyembuhan ditandai dengan intensitas nyeri yang berkurang secara bertahap sehingga ibu dapat memulai aktivitasnya kembali.
\end{abstract}

Tujuan: Penelitian ini bertujuan untuk mengetahui perbedaan intensitas nyeri sebelum dan sesudah dilakukan ambulasi dini pada ibu postpartum dengan SC.

Metode: Responden pada penelitian ini adalah ibu postpartum dengan seksio sesar di Rumah Sakit Swasta Bekasi Timur, yang dilaksanankan pada bulan Agustus 2017 sampai bulan Januari 2018. Sampel penelitian ini adalah 40 responden dengan total sampling method. Pengukuran intensitas nyeri menggunakan skala wajah Wong \& Barker, instrument ambulasi dini menggunakan lembar observasi, analisis data menggunakan uji Wilcoxon.

Hasil: dari intervensi ambulasi dini pada hari pertama ibu berada dominan pada intensitas nyeri berat (75\%), pada hari kedua intensitas nyeri sedang $(77.5 \%)$ dan hari ketiga intensitas nyeri ringan $(75 \%)$. Nilai intensitas nyeri sebelum dan sesudah ambulasi dini menurun secara bertahap ditunjukkan pada hari pertama dengan nilai $\mathrm{P}$ value 0.004 , hari kedua $\mathrm{P}$ value 0.000 dan hari ketiga $\mathrm{P}$ value 0.000 . Hasil penelitian menunjukkan significant perubahan dan penuruan intensitas nyeri sebelum dan sesudah dilakukan ambulasi dini pada ibu postpartum dengan SC selama tiga hari perawatan di RS. Ambulasi dini sangat efektif sebagai salah satu metode menurunkan intensitas nyeri pada ibu post SC.

Kata kunci : ambulasi dini, nyeri, seksio sesar 
Dinamika Kesehatan Jurnal Kebidanan dan Keperawatan Vol 10 No. 1 Juli 2019 ( ISSN: 2086-3454 EISSN: 2549-4058)

url: http://ojs.dinamikakesehatan.unism.ac.id DOI : https://doi.org/10.33859/dksm.v10i1.390

Perbedaan Intensitas Nyeri Sebelum dan Sesudah Ambulasi Dini pada Ibu Postpartum Post Seksiosesar

Differences in Pain Intensity Before and After Early Ambulation in Postpartum Mothers

Post Section

Abstract

Background. Every mother who had experienced cesarean section, have a high intensity of pain that interrupted bounding attachment for their baby and caring for their self. Early mobilization started on six until twelve hours post cesarean section will increase the healing process with a sign with decrease the pain intensity gradually by time so the mother could start the daily activity.

Objective. The purpose of this research is to know to determine differences of pain intensity before and after the early mobilization of post SC mother for three days in the hospital.

Method. The study has inclusion criteria mother who had a cesarean section at east Bekasi in Private Hospital, in August 2017 until January 2018. The sample of this research was 40 respondents with a total sampling method. Measurement of pain intensity using Wong \& Barker faces scale, early mobilization instrument using observation sheet, data analysis using Wilcoxon test.

Result. The scale of pain intensity after early ambulation on the first day majority mothers have severe pain (75\%), on the second day have moderate pain (77.5\%) and finally on the third day have mild pain (75\%). The pain intensity gradually over time was decrease before and after implementation on the first day with p. value 0.004, the second day with p. value 0.000 and the third day with p. value 0.000.

Conclusion. The early mobilization was effective to decrease the level of pain for mother who had experienced cesarean section. The method was useful for cesarean mothers when hospitalize.

Keywords : early mobilization, pain intensity, cesarean section 
Dinamika Kesehatan Jurnal Kebidanan dan Keperawatan Vol 10 No. 1 Juli 2019 ( ISSN: 2086-3454 EISSN: 2549-4058)

url: http://ojs.dinamikakesehatan.unism.ac.id DOI : https://doi.org/10.33859/dksm.v10i1.390

Perbedaan Intensitas Nyeri Sebelum dan Sesudah Ambulasi Dini pada Ibu Postpartum Post Seksiosesar

\section{Pendahuluan}

Ibu yang menjalani proses persalinan secara SC memiliki masalah utama dalam proses penyembuhan yaitu nyeri. Penatalaksanaan nyeri post SC yang kurang tepat dan akurat dapat menimbukan debilitas (menurunnya motivasi atau tenaga), serta menghambat kualitas hidup dan mengakibatkan depresi (Vaughn, Wichowski \& Bosworth, 2007). Menurut Smeltzer dan Bare (2002) intervensi nonfarmakologis belum banyak digunakan untuk mengurangi nyeri pasca SC, bahkan cenderung memandang obat sebagai satu-satunya intervensi untuk mengurangi nyeri. Salah satu intervensi nonfarmakologis untuk mengurangi nyeri adalah dengan ambulasi dini (Smeltzer dan Bare,2002).

Ambulasi dini dengan gerakkan sederhana sangat penting diperlukan khususnya pada pasien post SC karena akan mempengaruhi rat-rata dari komplikasi (Agarwal, 2016; Kasdu, 2017 dan Mettagin,
2009) seperti angka kesakitan seperti decompensasi pernafasan atau pnemonia, Deep Venous Thrombosis (DVT), infeksi saluran perkemihan, ileus, sepsis atau infeksi dan hal itu semua akan mempengaruhi hari rawat pasien atau LOS (Length of Stay), 70\% LOS menjadi lebih pendek di Rumah Sakit.

Ambulasi dini merupakan kunci untuk mengembalikan keadaan fisik menjadi normal dengan mempercepat proses penyembuhan luka, memperkuat otot sehingga mampu meningkatkan kemampuan aktifitas kegiatan harian dan perasaan sehat (Suvarna and Salunkhe, 2014 dan Harmanjyot; Sukhjit; Sikka, 2015).

Hasil penelitian Jyoti dan Kshirsagar (2014) menyatakan ambulasi dini signifikan dengan parameter kesehatan biophysiological yang meliputi nyeri pada luka insisi, kondisi payudara, kondisi abdomen dan gerakan peristaltik usus. Ambulasi dini setelah 6-8 jam dapat menolong menurunkan komplikasi 
Dinamika Kesehatan Jurnal Kebidanan dan Keperawatan Vol 10 No. 1 Juli 2019 ( ISSN: 2086-3454 EISSN: 2549-4058)

url: http://ojs.dinamikakesehatan.unism.ac.id DOI : https://doi.org/10.33859/dksm.v10i1.390

Perbedaan Intensitas Nyeri Sebelum dan Sesudah Ambulasi Dini pada Ibu Postpartum Post Seksiosesar

maternal dan angka kesakitan yang biasanya

menyertai pada tindakan seksio sesar (Mantle

Jill, Haslam Jeanette, and Barton Sue, 2005).

Promosi ambulasi dini ini dapat ditujukan kepada pasien yang dirawat termasuk yang mengalami operasi tulang belakang (Epstein, 2014). Promosi ambulasi dini secara tidak langsung dapat menurunkan biaya perawatan di RS. Pada penelitian Sahin dan Terzioglu (2015) mengatakan bahwa intervensi dengan menguyah permen karet, hidrasi oral dini dan ambulasi dini dapat meningkatkan motalitas usus, dan intervensi ini direkomendasikan selama perawatan rutin untuk menurunkan nyeri.

Data yang diperoleh dari Rumah Sakit Swasta Bekasi Timur ibu post partum dengan SC tahun 2015 adalah 665 ibu, 677 ibu di tahun 2016 dan pada tahun 20 januari hingga mei 2017 berkisar 35 ibu perbulannya. Wawancara tidak terstruktur ditemukan 10 ibu post SC rasa nyeri yang masih menetap dirasakan dan kurang memahami bagaimana melakukan ambulasi saat pertama kali, kurangnya informasi dari perawat maternitas dalam melakukan ambulasi dan ambulasi dini untuk mengurangi rasa nyeri. Tidak adanya kelas edukasi pasien post partum untuk menurunkan nyeri membuat tambahnya rasa kuatir dan takut bergerak selama perawatan di RS.

\section{Metode}

Penelitian ini merupakan penelitian kuantitatif dengan metode pre eksperimental design dengan melakukan analisis uji beda non parametric, dimana pengujian dilakukan untuk menentukan perbedaan intensitas nyeri sebelum dan sesudah dilakukan ambulasi dini pada ibu post SC di RS swasta di Bekasi Timur, dilakukan di bawah situasi terkendali dengan menggunakan one group pre test-post test design.

Variabel independen : ambulasi dini, sedangkan variable dependen adalah intensitas nyeri pada ibu post operasi seksio sesar (SC) 
Dinamika Kesehatan Jurnal Kebidanan dan Keperawatan Vol 10 No. 1 Juli 2019 ( ISSN: 2086-3454 EISSN: 2549-4058)

url: http://ojs.dinamikakesehatan.unism.ac.id DOI : https://doi.org/10.33859/dksm.v10i1.390

Perbedaan Intensitas Nyeri Sebelum dan Sesudah Ambulasi Dini pada Ibu Postpartum Post Seksiosesar

dengan skala wajah Wong dan Barker nilai 0-

10.

Pengambilan sample dengan metode accisidental sampling sebanyak $40 \mathrm{ibu}$ sesuai dengan kriteria inklusi dan setelah 6-12 jam post SC, bersedia menjadi responden dengan menandatangani informend consect dan bersedia dilakukan ambulasi dini.

Alat pengumpulan data berupa lembar observasi pretest dan posttest untuk untuk mendokumentasikan hasil pengukuran skala nyeri.

$$
\text { Analisis univariat menggunakan }
$$

Wilcoxon test untuk varibel intensitas nyeri baik sebelum dan sesudah intervensi selama tiga hari. Analisa bivariate menggunakan Uji Beda Statistik non Parametrik yang dilakukan adalah dengan uji $t$-test, yaitu untuk mengetahui perbedaan intensitas nyeri sebelum dan setelah intervensi (before-after) pada kelompok intervensi selama tiga hari.

\section{Hasil}

Tabel 1

Distribusi Frekuensi Intensitas Nyeri Hari Pertama, Kedua dan Ketiga Sebelum dan Sesudah Ambulasi Dini Pada Ibu Post SC

\begin{tabular}{|c|c|c|c|c|c|c|c|c|}
\hline \multirow{2}{*}{ Intervensi } & \multicolumn{8}{|c|}{ Intensitas Nyeri } \\
\hline & & $\begin{array}{l}\text { idak } \\
\text { yeri }\end{array}$ & & $\begin{array}{l}\text { yeri } \\
\text { ngan }\end{array}$ & & $\begin{array}{l}\text { eri } \\
\text { lang }\end{array}$ & & $\begin{array}{l}\text { yeri } \\
\text { erat }\end{array}$ \\
\hline $\begin{array}{l}\text { Hari } \\
\text { Pertama }\end{array}$ & $\mathrm{N}$ & $\%$ & $\mathrm{n}$ & $\%$ & $\mathrm{n}$ & $\%$ & $\mathrm{n}$ & $\%$ \\
\hline Sebelum & 0 & $0 \%$ & 0 & $0 \%$ & 3 & $7.5 \%$ & 37 & $92.5 \%$ \\
\hline Sesudah & 0 & $0 \%$ & 0 & $0 \%$ & 10 & $25 \%$ & 30 & $75 \%$ \\
\hline $\begin{array}{l}\text { Hari } \\
\text { Kedua } \\
\text { Sebelum }\end{array}$ & 0 & $0 \%$ & 12 & $30 \%$ & 28 & $70 \%$ & 0 & $0 \%$ \\
\hline Sesudah & 0 & $0 \%$ & 9 & $22.5 \%$ & 30 & $75 \%$ & 1 & $2.5 \%$ \\
\hline $\begin{array}{l}\text { Hari } \\
\text { Ketiga } \\
\text { Sebelum }\end{array}$ & 0 & $0 \%$ & 24 & $60 \%$ & 16 & $40 \%$ & 0 & $0 \%$ \\
\hline Sesudah & 9 & $22.5 \%$ & 31 & $77.5 \%$ & 0 & $0 \%$ & 0 & $0 \%$ \\
\hline
\end{tabular}

Tabel 2

Perbedaan Intensitas Nyeri Sebelum dan Sesudah Mobilisasi Dini Pada Ibu Post SC

\begin{tabular}{lcccccc}
\hline \multicolumn{1}{c}{$\begin{array}{c}\text { Intensitas } \\
\text { Nyeri }\end{array}$} & $\mathrm{n}$ & Mean & $\begin{array}{c}\text { Std } \\
\text { Deviasi }\end{array}$ & $\begin{array}{c}\mathrm{P} \\
\text { Value }\end{array}$ & $\mathrm{Z}$ \\
\hline \multirow{2}{*}{ Hari I } & Pre & 40 & 8.13 & 1.114 & & \\
& Post & 40 & 7.33 & 1.095 & 0.004 & -2.898 \\
Hari II & Pre & 40 & 5.95 & 1.154 & & \\
& Post & 40 & 4.13 & 0.966 & 0.000 & -5.329 \\
Hari III & Pre & 40 & 3.43 & 0.701 & & \\
\hline
\end{tabular}

\section{Pembahasan}

Hasil penelitian Jyoti dan Kshirsagar (2014) mengatakan ambulasi dini signifikan dengan parameter kesehatan biophysiological yang pada luka insisi, kondisi payudara, kondisi abdomen dan gerakan peristaltic 
Dinamika Kesehatan Jurnal Kebidanan dan Keperawatan Vol 10 No. 1 Juli 2019 ( ISSN: 2086-3454 EISSN: 2549-4058)

url: http://ojs.dinamikakesehatan.unism.ac.id DOI : https://doi.org/10.33859/dksm.v10i1.390

Perbedaan Intensitas Nyeri Sebelum dan Sesudah Ambulasi Dini pada Ibu Postpartum Post Seksiosesar

usus. Ambulasi dini setelah 6-8 jam dapat menolong menurunkan komplikasi internal dan angka kesakitan yang biasanya menyertai pada tindakan sektio caesare (Mantle Jill, Haslam Jeanette, and Barton Sue, 2005).

Berdasarkan analisis table 1.1 disimpulkan bahwa ada penurunan intensitas nyeri secara signifikan sebelum dan sesudah ambulasi dini di hari pertama sampai ketiga, hal ini dapat dilihat dari hasil analisis dengan menggunakan Wilcoxon Signed Ranks Test. Pada hari pertama sesudah intervensi skala nyeri masih berkisar 7-10 namun ada 10 ibu yang sudah mengalami penuruan nyeri menjadi nyeri sedang. Demikian juga hari kedua dan ketiga, dan pada hari terakhir di rawat ada 9 ibu yang bebas nyeri pada hari ketiga. Hasil penelitian ini didukung oleh Chin (2012) yang menyatakan dimensi nyeri pada 24-48 jam post SC skala nyeri akan menurun dengan rerata 2.75. Ambulasi dini membuat masa pada otot menjadi kuat untuk melakukan aktivitas sehari-hari (Suvarna dan Salunke, 2014; Harmanjyot; Sukhjit; Sikka, 2015). Nyeri setelah SC yang bersifat menetap akan menyebabkan postpartum depresi dan kecemasan selama enam minggu periode postpartum (Daniel, 2014).

Tabel 1.2 hasil analisa uji beda dengan wilcoxon test hari pertama menunjukkan nilai mean dan st.deviasi post test 7.33 lebih kecil dari nilai pre test yaitu 8.13. Pada intensitas nyeri hari pertama sebelum mobilisasi adalah nyeri berat dengan nilai $\mathrm{Z}$ yang didapat sebesar -2.898 dengan $\mathrm{p}$ value 0.004 dimana kurang dari batas kritis penelitian 0.05, dengan demikian ada perbedaan intensitas nyeri pasien post sc sebelum dan sesudah dilakukan latihan hari pertama sehingga mobilisasi dini efektif dilakukan untuk menurunkan intensitas nyeri pada ibu post SC.

Pada hari kedua menunjukkan nilai mean dan st.deviasi post test 4.13 lebih kecil dari nilai pre test yaitu 5.95. Pada intensitas nyeri hari kedua sebelum mobilisasi 
Dinamika Kesehatan Jurnal Kebidanan dan Keperawatan Vol 10 No. 1 Juli 2019 ( ISSN: 2086-3454 EISSN: 2549-4058)

url: http://ojs.dinamikakesehatan.unism.ac.id DOI : https://doi.org/10.33859/dksm.v10i1.390

Perbedaan Intensitas Nyeri Sebelum dan Sesudah Ambulasi Dini pada Ibu Postpartum Post Seksiosesar

adalah nyeri sedang dengan nilai $\mathrm{Z}$ yang didapat sebesar -5.329 dengan $\mathrm{p}$ value 0.000 dimana kurang dari 0.05 , dengan demikian ada perbedaan intensitas nyeri pasien post SC sebelum dan sesudah dilakukan latihan hari kedua sehingga mobilisasi dini efektif dilakukan untuk menurunkan intensitas nyeri pada ibu post SC.

Hasil analisa uji beda dengan wilcoxon test hari ketiga menunjukkan nilai mean dan st.deviasi post test 1.43 lebih kecil dari nilai pre test yaitu 3.43. Pada intensitas nyeri hari kedua sebelum mobilisasi adalah nyeri ringan dengan nilai $\mathrm{Z}$ yang didapat sebesar 5.520 dengan $\mathrm{p}$ value 0.000 dimana kurang dari 0.05, dengan demikian ada perbedaan intensitas nyeri pasien post SC sebelum dan sesudah dilakukan latihan hari ketiga sehingga mobilisasi dini efektif dilakukan untuk menurunkan intensitas nyeri pada ibu post SC. Hasil penelitian ini sejalan dengan dengan penelitian Harmanjyot; Sukhjit; Sikka, (2015) yang menyatakan hasil penelitian menunjukkan bahwa terdapat perbedaan yang signifikan antara nyeri pasca operasi setelah dilakukan mobilisasi dini. Penelitian lain yang mendukung penelitian ini adalah Kaur (2015) yang mengatakan ambualsi dini dimulai 6 jam setelah operasi SC dapat menurunkan komplikasi yang akan terjadi. Karakaya (2012) dengan melakukan ambulasi dini selama dua hari secara significant dapat menurunkan nyeri pada luka insisi dan meningkatkan fungsi tubuh untuk beraktifitas sehingga menurunkan angak kesakitan dan meningkatkan kualitas hidup ibu postpartum serta meningkatkan kemampuan untuk merawat bayinya.

Memfasilitasi atau membantu ibu postpartum SC dengan ambulasi dini sangat efektif menurunkan intensitas nyeri. Perawat diharapkan mampu melakukan pengkajian nyeri dengan tepat sehingga mampu memberikan asuhan keperawatan pasien terkait nyeri demi meningkatkan rasa nyaman pada ibu postpartum dan bahwa mobilisasi dini merupakan suatu aspek yang terpenting pada 
Dinamika Kesehatan Jurnal Kebidanan dan Keperawatan Vol 10 No. 1 Juli 2019 ( ISSN: 2086-3454 EISSN: 2549-4058)

url: http://ojs.dinamikakesehatan.unism.ac.id DOI : https://doi.org/10.33859/dksm.v10i1.390

Perbedaan Intensitas Nyeri Sebelum dan Sesudah Ambulasi Dini pada Ibu Postpartum Post Seksiosesar

fungsi fisiologis karena hal itu esensial

untuk mempertahankan kemandirian ibu selama periode postpartum (Bobak dkk, 2004).

Dube, Kshirsagar dan Durgawale (2014) melakukan ambulasi dini selama lima hari dan memberikan informasi pada tahap sebelum operasi serta merupakan kegiatan rutin bagi perawat maternitas dalam memberikan asuhan kepada ibu postpartum dengan SC memiliki efek positif dibandingkan dengan kelompok yang tidak merencanakan dan mengimplementasikan ambulasi dini. Potter (2007) dan Porter, dkk (2007) menekankan komunikasi yang kurang antara perawat dan ibu, perasaan takut yang berlebihan pada saat setelah operasi SC merupakan faktor utama yang menyebabkan tingginya angka stress pada ibu postpartum, sehingga ibu takut melakukan aktivitas harian seperti menyusui dan merawat dirinya sendiri.

Perilaku caring perawat sangat diperlukan dalam perawatan di area aternitas ini, dengan Being with atau bersama ibu, mengetahui kesulitan yang dihadapi dan mampu mendampingi ibu untuk mau melakukan ambulasi dini melalui komunikasi yang baik, akan mengurangi dampak negative kedepan seperti trauma melahirkan, depresi, stress, menyalahkan diri sendiri dan krisis ketidakpercayaan diri untuk kehamilan berikutnya (Gamble, 2005). Menurut peneliti mobilisasi dini merupakan kunci untuk mengembalikan keadaan fisik menjadi normal sehingga penurunan nyeri yang dialami pasien lebih cepat teratasi, dan pasien mampu melakukan aktifitas kegiatan harian dengan perasaan yang nyaman dan sehat.

\section{Ucapan Terima Kasih}

- STIKes Sint Carolus

- RS swasta di Bekasi timur

- Responden ibu-ibu postpartum dengan SC

\section{Daftar Pustaka}

Agarwal, S., Raza, S., Moiz, J. A., Anwer, S., \& Alghadir, A. H. (2016). Effects of two different mobilization techniques on pain, 
Dinamika Kesehatan Jurnal Kebidanan dan Keperawatan Vol 10 No. 1 Juli 2019 ( ISSN: 2086-3454 EISSN: 2549-4058)

url: http://ojs.dinamikakesehatan.unism.ac.id DOI : https://doi.org/10.33859/dksm.v10i1.390

Perbedaan Intensitas Nyeri Sebelum dan Sesudah Ambulasi Dini pada Ibu Postpartum Post Seksiosesar

range of motion and functional disability in patients with adhesive capsulitis: a comparative study. Journal of Physical Therapy Science, 28(12), 3342-3349. http://doi.org/10.1589/jpts.28.3342

Bobak, Lowdermilk, Jensen, 2004, Buku Ajar Keperawatan Maternitas / Maternity Nursing (Edisi 4), Alih Bahasa Maria A. Wijayati, Peter I. Anugerah, Jakarta : EGC.

Chin, E.G. (2012). The symptom experience of postnatal pain after cesarean birth (Order No. 3558486). ProQuest Dissertations \& Theses Global. (1342608031). Retrieved from

http://search.proquest.com/docview/13426 08031 ? accountid $=17242$

Daniel, C. A. (2014). The effect of psychosocial factors on acute and persistent pain after childbirth (Order No. 10035735). Available from ProQuest Dissertations \& Theses Global. (1774013680). Retrieved from

https://search.proquest.com/docview/17740 13680 ? accountid $=17242$

Dube, Jyoti V; Kshirsagar, N. S. ; Durgawale, P.M. (2013). Effect of planned early ambulation on selected postnatal activities of post caeserean patients. International Journal of Health Sciences and Research (IJHSR). 3(12): 110-118. Retrieved from http://www.scopemed.org/?mno=49564

Epstein, N. E. (2014). A review article on the benefits of early mobilization following spinal surgery and other medical/surgical procedures. Surgical Neurology International, 5(Suppl 3), S66-S73. Diunduh pada tanggal 15 July 2017 di http://doi.org/10.4103/21527806.130674 .
Gamble, J., Creedy, D., Moyle, W., Webster, J., McAllister, M., \& Dickson, P. (2005). Effectiveness of a counseling intervention after a traumatic childbirth: a randomized controlled trial. Birth, 32(1), 11-19.

Jyoti V. Dub and N. S. Kshirsagar. (2014). Effect of Planned Early Recommended Ambulation Technique on Selected Post caesarean Biophysiological Health Parameters, Journal of Krishna Institute of Medical Sciences University, diunduh pada tanggal 15 July 2017 di http://www.jkimsu.com/jkimsuvol3no1/JKI MSU

Kaur, H., Kaur, S., \& Sikka, P. (2015). A quasiexperimental study to assess the effectiveness of early ambulation in postoperative recovery among post-caesarean mothers admitted in selected areas of Nehru Hospital, PGIMER, Chandigarh. Nursing and Midwifery Research, 11(1), 33.

Karakaya, İ. Ç., Yüksel, İ., Akbayrak, T., Demirtürk, F., Karakaya, M. G., Özyüncü, Ö., \& Beksaç, S. (2012). Effects of physiotherapy on pain and functional activities after cesarean delivery. Archives of Gynecology and Obstetrics, 285(3), 621627.

K,Harmanjyot; K,Sukhjit ; Sikka, Pooja. (Jan, 2015). A quasi-experimental study to assess the effectiveness of early ambulation in post-operative recovery among post- caesarean mothers admitted in selected areas of Nehru Hospital, PGIMER,

Kasdu D., 2003. Operasi Caesar Masalah dan Solusinya, Jakarta: Puspa Swara.

Mantle Jill, Haslam Jeanette, Barton Sue. Physiotherapy in Obstetrics and 
Dinamika Kesehatan Jurnal Kebidanan dan Keperawatan Vol 10 No. 1 Juli 2019 ( ISSN: 2086-3454 EISSN: 2549-4058)

url: http://ojs.dinamikakesehatan.unism.ac.id DOI : https://doi.org/10.33859/dksm.v10i1.390

Perbedaan Intensitas Nyeri Sebelum dan Sesudah Ambulasi Dini pada Ibu Postpartum Post Seksiosesar

Gynecology. 2nd Ed. A Division of Reed

Elsevier Pvt. Ltd: 2005: 206-238pp.

Porter, M., Van Teijlingen, E., Chi Ying Yip, L., \& Bhattacharya, S. (2007). Satisfaction with cesarean section: Qualitative analysis of open-ended questions in a large postal survey. Birth, 34(2), 148-154.

Potter, P, A., \& Perry,A, G., (2005). Fundamental Keperawatan. Alih Bahasa Yasmin Asih, SKp. Jakarta : EGC.

Sahin E, Terzioglu F. (Dec, 2015). The Effect of Gum Chewing, Early Oral Hydration, and Early Mobilization on Intestinal Motility After Cesarean Birth. Worldviews Evid Based Nurs.;12(6):3808. doi: 10.1111/wvn.12125. Epub 2015 Nov 27. Diunduh pada tanggal 15 July 2017 di https://www.ncbi.nlm.nih.gov/pubme d/26613392

Smeltzer, S. C., \& Bare, B. G. (2002). Buku Ajar Keperawatan Medikal Bedah Brunner dan Suddarth. Alih bahasa oleh Agung Waluyo...(dkk), EGC, Jakarta.

Suvarna, V.M; Jyoti, Salunkhe A. (2014). A study to assess the effectiveness of early ambulation on selected aspects of post operative recovery among the women who have undergone LSCS at Krishna hospital, Karad. International Journal of Health Science \& Research;4(12):230-239. Diunduh pada tanggal 15 July 2017 di http://www.ijhsr.org/IJHSR_Vol.4_Issue.1 2_Dec2014/35.pdf

Vaughn, F., Wichowski, H., \& Bosworth, G. (2007). Does preoperative anxiety level predict postoperative pain?.AORN journal, 85(3), 589-604. 